\title{
Dying at home or in an institution: perspectives of Dutch physicians and bereaved relatives
}

\author{
Agnes van der Heide • Elsbeth de Vogel-Voogt • \\ Adriaan Ph. Visser • Carin C. D. van der Rijt • \\ Paul J. van der Maas
}

Received: 10 November 2006 / Accepted: 22 March 2007 / Published online: 20 April 2007

(C) Springer-Verlag 2007

\begin{abstract}
Introduction Previous studies have shown that most people prefer to die at their own home. We investigated whether physicians or bereaved relatives in retrospect differently appreciate the dying of patients in an institution or at home. Materials and methods of 128 patients with incurable cancer who were followed in the last phase of their lives, 103 passed away during follow-up. After death, physicians filled out a written questionnaire for 102 of these patients, and 63 bereaved relatives were personally interviewed. Results Of 103 patients, 49 died in an institution (mostly a hospital), and 54 died at home (or in two cases in a homelike situation). Patients who had been living with a partner relatively often died at home. Bereaved relatives knew of the patient's wish to die at home in 25 out of 63 cases; 20 of these patients actually died at home. Thirty-one patients had no known preference concerning their place of dying. Most symptoms and the care provided to address them were equally prevalent in patients dying in an institution and patients dying at home. Bereaved relatives were in general quite satisfied about the provision of medical and nursing care in both settings.
\end{abstract}

A. van der Heide $(\bowtie) \cdot$ E. de Vogel-Voogt $\cdot$ P. J. van der Maas Department of Public Health, Erasmus MC,

University Medical Center Rotterdam,

P.O. Box 2040, 3000 CA Rotterdam, The Netherlands

e-mail: a.vanderheide@erasmusmc.nl

\section{A. P. Visser}

Helen Dowling Institute, Center for Psycho-oncology,

P.O. Box 85061, 3508 AB Utrecht, The Netherlands

C. C. D. van der Rijt

Department of Medical Oncology, Erasmus MC,

University Medical Center Rotterdam,

P.O. Box 2040, 3000 CA Rotterdam, The Netherlands
Conclusion We conclude that most patients' preferences concerning the place of dying can be met. In about half of all cases, patients do not seem to have a clear preference concerning their place of dying, which is apparently not a major concern for many people. We found no indication that dying in an institution or at home involves major differences in the process and quality of dying.

Keywords End-of-life care · Place of death .

Cancer patients · Quality of dying

\section{Introduction}

The two most important events in life, that is, birth and death, relatively often occur at home in The Netherlands. Over the period 1995-2000, around one third of all Dutch births were home deliveries [1]. Further, in 2001, about $40 \%$ of all deaths have been found to occur at home, $40 \%$ in hospital, and about $20 \%$ in nursing homes [2]. Medical care in The Netherlands is strongly founded on home-based general practice. General practitioners or family physicians provide all basic medical care to outpatients and serve as a gate door to specialized care for patients with more complex health problems.

In 2003 , around $45 \%$ of deaths due to cancer occurred at home in The Netherlands [3]. In the UK, the percentage of cancer deaths at home is lower and falling, from $27 \%$ in 1994 to $22 \%$ in 2003 [4]. In a study of the place of death of cancer patients in the Houston area, USA, 35\% died at home [5]. End-of-life care is thus, especially in The Netherlands, rather often provided in the home situation by general practitioners, home-care nurses, and informal caregivers. Research has shown that dying at home is 
usually preferred over dying in an institution, in The Netherlands as well as in other countries [6]. Such a preference seems to be predominantly shaped by whether or not people have sufficient informal carer resources [7]. In contrast, people who are concerned about the medical management of their symptoms may appreciate the easy access to professional caregivers in an institutional setting. Concerns about burdening relatives have also been found to contribute to a wish to die in an institution [7]. The finding that people's wish to die at home becomes less predominant when death is nearing may be related to such concerns, as heavily burdening relatives with care duties is one of the most commonly recognized threats to a peaceful dying process [6]. A gradual shift in preference may also be due to the growing awareness of seriously ill people that dying sometimes involves problems and symptoms that are best treated by professional caregivers in an institutional setting. Finally, differential experiences of services also influence people's preferences [7].

Enabling people to make genuine choices about their end-of-life care and to die at the place they prefer is often seen as a major challenge to current end-of-life care [8-10]. Home-care patients have been reported to have more control over the effects of their illness, medical care, and treatment received than patients receiving institutional care [11]. However, it is unclear if the relatively high home death rate in The Netherlands is really beneficial to the quality of death and dying. Little is known about the experiences of dying patients and their caregivers in different health care settings. We investigated to what extent dying in an institution or at home involves differences in care and its appreciation by physicians and bereaved relatives.

\section{Materials and methods}

\section{Patients}

This study concerns a sub-sample of a cohort of 128 patients with advanced breast cancer, colorectal cancer, ovary cancer, lung cancer, or prostate cancer, who were followed for a study on end-of-life care needs and practices during the last stage of their lives [12]. Of these patients, 103 died within the time frame during which we were able to approach attending clinical specialists, general practitioners, and bereaved relatives for an after-death data collection. In 102 cases, physicians were willing to fill out a written questionnaire on the medical treatment and dying process of these patients: Questionnaires were filled out by clinical specialists in 30 cases, by general practitioners in 17 cases, and by both in 55 cases. Relatives who had been closely involved with the patient could be contacted in 91 cases; 63 gave their written consent to be personally interviewed at their own home. The reason for not participating was most often that relatives expected participation to be too burdensome. The patients for whom bereaved relatives participated in an interview had on average a longer disease duration (33 vs 21 months; $p=0.03)$ and were more often women (59 vs $28 \%$; $p=0.004)$ than other patients.

The Medical Ethical Committee of the Erasmus MC, University Medical Center Rotterdam approved the research protocol.

Questionnaire for attending physicians

As soon as we were informed of the death of a patient, physicians received a self-developed written questionnaire addressing the end-of-life medical treatment and decisionmaking. The median time between the patient's death and filling out the questionnaire was 12.5 weeks (range, 1 to 59 weeks). The questions on end-of-life decision-making were based upon questionnaires that have proven to yield valid information in previous studies $[2,13]$. In cases where both a clinical specialist and a general practitioner filled out a questionnaire, the information about the patients' anti-tumor treatment history, medical decision-making, and any 'negative' aspects of the dying process were considered to be additive.

\section{Interview with bereaved relatives}

Interviewers were trained to carry out interviews with vulnerable people during a 2-day course. The interviews were on average held 4.9 months after the patient's death (range, 0.8-9.5 months). The interview schedule included the following topics: personal characteristics of the bereaved relatives, such as age, sex, and relationship with the patient; symptoms of the patient, that is, loss of appetite, pain, fatigue, dyspnoea, nausea, mouth or mucous problems, incontinence, bedsores, confusion, anxiety, and depression; and whether or not the patient was treated for these symptoms. The patient symptom list was based upon the European Organization for Research and Treatment of Cancer Quality of Life Questionnaire C30 $[14,15]$ and the Problems and Needs in Palliative Care questionnaire $[16,17]$ and completed with psychological symptoms. Further, contacts with health care professionals, admission to hospital or other care institutions, the actual and preferred place of death, and problems in end-of-life care during the last 3 days of life were assessed using scales from the Voices of Informal Carers-Evaluation of Services (VOICES) questionnaire [18]. Finally, we asked the bereaved relatives about the burden of care giving. We adapted 
several questions from the Caregiver Reaction Assessment to make them applicable for an after-death interview with bereaved relatives [19].

\section{Statistical analyses}

We compared the characteristics of patients who died in an institution with the characteristics of patients who died at home. Student's $t$ tests and $\chi^{2}$ tests were used to assess the statistical significance of differences between both groups. All analyses were done using the Statistical Package for the Social Sciences version 11.0.

\section{Results}

The characteristics of all 103 deceased patients and of 63 patients for whom an after-death interview with a bereaved relative was available are presented in Table 1 . The mean age at death of all patients was 65 years; 48 patients (47\%) were women. The most common types of cancer were lung cancer (48 patients) and breast cancer (19 patients). Of all 103 patients, 49 died within an institution: 35 patients died at a hospital department, 6 patients died after having been admitted to a department within a hospital, nursing home, or home for the elderly that was specialized in care for

Table 1 Characteristics of patients and bereaved relatives

\begin{tabular}{|c|c|c|}
\hline Characteristics & $\begin{array}{l}\text { All deceased patients } \\
(N=103)\end{array}$ & $\begin{array}{l}\text { Deceased patients for whom a relative } \\
\text { was interviewed }(N=63)\end{array}$ \\
\hline \multicolumn{3}{|l|}{ Patients } \\
\hline Age at death, in years [mean (SD)] & $65(11)$ & $64(11)$ \\
\hline \multicolumn{3}{|l|}{$\operatorname{Sex}[n / N(\%)]$} \\
\hline Female & $48 / 103$ (47) & $37 / 63(59)$ \\
\hline \multicolumn{3}{|l|}{ Living arrangement $[n / N(\%)]$} \\
\hline With partner & $76 / 103(74)$ & $47 / 63(75)$ \\
\hline \multicolumn{3}{|l|}{ Education $[n / N(\%)]$} \\
\hline Low $^{\mathrm{a}}$ & $71 / 102(70)$ & $41 / 63(65)$ \\
\hline \multicolumn{3}{|l|}{ Religion $[n / N(\%)]$} \\
\hline Religious & $62 / 103(60)$ & $40 / 63(63)$ \\
\hline \multicolumn{3}{|l|}{ Urbanization $[n / N(\%)]$} \\
\hline Living in urban area ${ }^{\mathrm{b}}$ & $72 / 103(70)$ & $46 / 63(73)$ \\
\hline \multicolumn{3}{|l|}{ Primary tumor site $[n / N(\%)]$} \\
\hline Lung & 48/103 (47) & $31 / 63(49)$ \\
\hline Breast & 19/103 (18) & $14 / 63(22)$ \\
\hline Other & $36 / 103(35)$ & $18 / 63(29)$ \\
\hline \multicolumn{3}{|l|}{ History of anti-tumor treatment $[n / N(\%)]$} \\
\hline Surgery & $45 / 102(44)$ & $26 / 62(42)$ \\
\hline Chemotherapy/hormone therapy & $84 / 101(83)$ & $51 / 61(84)$ \\
\hline Radiotherapy & $54 / 101(54)$ & $36 / 61(59)$ \\
\hline \multicolumn{3}{|l|}{ Place of death } \\
\hline Institution $[n / N(\%)]$ & 49/103 (48) & $29 / 63(46)$ \\
\hline Hospital & $35 / 49$ & $24 / 29$ \\
\hline End-of-life care unit & $6 / 49$ & $2 / 29$ \\
\hline Hospice & $4 / 49$ & $3 / 29$ \\
\hline Nursing home/home for the elderly & $4 / 49$ & - \\
\hline At home or in a home-like situation $[n / N(\%)]$ & $54 / 103(52)$ & $34 / 63(54)$ \\
\hline At patient's own home & $52 / 54$ & $32 / 34$ \\
\hline Elsewhere & $2 / 54$ & $2 / 34$ \\
\hline \multicolumn{3}{|l|}{ Bereaved relatives } \\
\hline Age at the time of dying of the patient, in years [mean (SD)] & - & $55(15)$ \\
\hline \multicolumn{3}{|l|}{$\operatorname{Sex}[n / N(\%)]$} \\
\hline Female & - & $40 / 63(63)$ \\
\hline \multicolumn{3}{|l|}{ Relative was patient's $[n / N(\%)]$ : } \\
\hline Spouse & - & $39 / 63(62)$ \\
\hline Son or daughter & - & $19 / 63(30)$ \\
\hline Other relationship & - & $5 / 63(8)$ \\
\hline
\end{tabular}

${ }^{a}$ Low education: lower vocational, lower secondary general education, or primary school

${ }^{\mathrm{b}}$ Living in an urban area: patients who were treated as an outpatient in a hospital inside the Rotterdam area 
dying patients, 4 patients died within a general department of a nursing home or home for the elderly, and 4 patients died in a hospice. The remaining 54 patients died at home or in a home-like situation: 52 patients died in their own homes, 1 patient died in the home of a son, and 1 patient died during a holiday on a boat. The only significant difference between patients dying in an institution and patients dying at home concerned the percentage who had lived with a partner, which was $63 \%$ for patients who died in an institution and $83 \%$ for patients who died at home. All other characteristics of patients and relatives that are listed in Table 1 were similar in both groups. The characteristics of the group of patients for whom a relative could be interviewed were also similar to the characteristics of the total group. The interviewed relative was the patient's spouse in 39 out of the 63 cases; in 19 cases, it was a son or daughter, and in 5 cases, another relative. The majority of relatives were women, and their mean age was 55 years.

Some aspects of medical care are shown in Table 2. In both groups, physicians reported that about two thirds of the patients had died peacefully. Patients who died in an institution had less often (37\%) been ready to die than patients who died at home (71\%). Agitation was a common problem during the dying process. Most patients in both settings had been unconscious before death. Physicians had discussed a number of end-of-life decisions each with about one third of their patients: This holds for decisions to forgo potentially life-prolonging treatment, intensive treatment of pain, and active euthanasia. Sedation was the only treatment option that was discussed slightly more often with patients who died in an institution. Life had actually been shortened due to the forgoing of potentially lifeprolonging treatment or to the use of potentially lifeshortening drugs in about one third of all cases in both settings. Such medical decisions were usually made with clear consent of the patient, and life was generally shortened by less than 1 week.

Bereaved relatives reported in 25 out of 63 cases that the patient had preferred to die at home (Table 3). Two patients had preferred to die in the hospital, 3 in a hospice, 2 elsewhere, and for 31 patients, the relative indicated that the patient had no clear preference. Most patients who had a preference died at the place they preferred, except for five patients who preferred home but died in the hospital. Patients who died in an institution had stayed there for on average 7 days. The number of transfers during 3 months before death was larger for patients who died in an institution (mean 1.9) than for patients who died at home

Table 2 Dying in an institution or at home: the physician's perspective

\begin{tabular}{|c|c|c|c|}
\hline & \multicolumn{2}{|l|}{ Place of death } & \multirow[t]{2}{*}{$P$ value $\chi^{2}$ tes } \\
\hline & $\begin{array}{l}\text { In institution }(N=49) \\
N(\%)\end{array}$ & At home $(N=54)$ & \\
\hline \multicolumn{4}{|l|}{ Physician's evaluation of dying process ${ }^{\mathrm{a}}$} \\
\hline Patient died peacefully & $28 / 41(68)$ & $29 / 42(69)$ & 0.94 \\
\hline Patient was able to say goodbye to relatives & $26 / 40(65)$ & $33 / 44(75)$ & 0.32 \\
\hline Patient was ready to die & $15 / 41(37)$ & $31 / 44(71)$ & 0.002 \\
\hline Patient died suddenly and unexpectedly & $13 / 42(31)$ & $14 / 44(32)$ & 0.93 \\
\hline Patient's dying was preceded by period of agitation & $25 / 40(63)$ & $29 / 41(71)$ & 0.43 \\
\hline Patient's dying was preceded by period of unconsciousness & $30 / 39(77)$ & $26 / 42(62)$ & 0.14 \\
\hline \multicolumn{4}{|c|}{$\begin{array}{l}\text { Physician discussed with patient medical decisions that could shorten } \\
\text { life }\end{array}$} \\
\hline Forgoing treatment & $13 / 49(27)$ & $15 / 50(30)$ & 0.70 \\
\hline Intensified pain treatment & $16 / 49(33)$ & $16 / 50(32)$ & 0.95 \\
\hline Sedation & $15 / 49(31)$ & $8 / 50(16)$ & 0.09 \\
\hline Euthanasia & $18 / 49(37)$ & $19 / 50(38)$ & 0.90 \\
\hline \multicolumn{4}{|l|}{ Life was possibly shortened due to } \\
\hline Forgoing treatment & $15 / 47(32)$ & $14 / 52(27)$ & 0.59 \\
\hline With clear consent of the patient & $11 / 12$ & $12 / 13$ & \\
\hline Life was shortened by more than 1 week & $4 / 11$ & $0 / 9$ & \\
\hline Use of potentially life-shortening drugs & $16 / 46(35)$ & $13 / 45(29)$ & 0.55 \\
\hline With clear consent of the patient & $12 / 14$ & $9 / 10$ & \\
\hline With the explicit goal of shortening life & $1 / 16$ & $4 / 13$ & \\
\hline Life was shortened by more than 1 week & $1 / 13$ & $2 / 10$ & \\
\hline
\end{tabular}

Information as provided by clinical specialist $(n=85)$ and/or general practitioner $(n=72)$. In case of conflicting answers concerning history of treatment, the information as provided by the clinical specialist prevailed. In all other cases, both sources were considered valid.

${ }^{a}$ Statement was considered true if neither the clinical specialist nor the general practitioner considered it untrue. 
Table 3 Preferred and actual place of death

\begin{tabular}{|c|c|c|c|c|c|}
\hline \multirow[t]{3}{*}{ Preferred place of death ${ }^{\mathrm{a}}$} & \multicolumn{4}{|c|}{ Actual place of death } & \multirow[t]{3}{*}{ Total $(N=63)$} \\
\hline & \multicolumn{2}{|c|}{ In institution } & \multicolumn{2}{|l|}{ At home } & \\
\hline & $\begin{array}{l}\text { Hospital } \\
(N=24)\end{array}$ & $\begin{array}{l}\text { Hospice/end-of-life care unit } \\
(N=5)\end{array}$ & $\begin{array}{l}\text { At patient's own home } \\
(N=32)\end{array}$ & $\begin{array}{l}\text { Elsewhere } \\
(N=2)\end{array}$ & \\
\hline Hospital & 2 & & & & 2 \\
\hline Hospice & & 3 & & & 3 \\
\hline At home & 5 & & 20 & & 25 \\
\hline Other place & 1 & 1 & & & 2 \\
\hline No (clear) preference & 16 & 1 & 12 & 2 & 31 \\
\hline
\end{tabular}

${ }^{\mathrm{a}}$ Information as provided by bereaved relative

(mean 1.2), and the number of medical specialties that were involved with the patient was also larger in institutions (mean 2.2) than at home (mean 1.8). Care involved on average six disciplines (medical and non-medical), both in institutions and at home.

During the last 3 days of life, a large proportion of patients in both settings suffered, according to the reports of bereaved relatives, from fatigue, loss of appetite, pain, dyspnoea, and mouth or mucus problems (Table 4). Patients dying in an institution were somewhat more often incontinent and more often suffered from anxiety. Patients dying at home slightly more often had bedsores. There were no statistically significant differences between the settings in the degree to which symptoms were addressed with some form of medical treatment, except for loss of appetite, for which 6 of 22 patients who died in an institution received treatment, but only 2 of 30 patients who died at home $(p=0.04)$. The bereaved relatives' evaluation of end-of-life care was in general positive in both settings. Some relatives of patients who died in an institution felt they had not sufficiently been

Table 4 Dying in an institution or at home: perspective of bereaved relative

\begin{tabular}{|c|c|c|c|c|}
\hline & \multicolumn{2}{|l|}{ Place of death } & \multirow[t]{2}{*}{$P$ value $t$ test } & \multirow[t]{2}{*}{$P$ value $\chi^{2}$ test } \\
\hline & In institution $(N=29)$ & At home $(N=34)$ & & \\
\hline Number of days patient stayed at place of death [mean (SD)] & $7(6)$ & $59(35)$ & 0.000 & \\
\hline Number of transfers [mean (SD)] & $1.9(1.7)$ & $1.2(1.3)$ & 0.047 & \\
\hline Number of disciplines involved with patient [mean (SD)] & $6.1(2.3)$ & $5.8(1.9)$ & 0.64 & \\
\hline Number of clinical specialties involved with patient [mean (SD)] & $2.2(1.2)$ & $1.8(0.8)$ & 0.011 & \\
\hline \multicolumn{5}{|l|}{ Patient $[n(\%)]$} \\
\hline Was fatigued & $22(79)$ & $29(88)$ & & 0.33 \\
\hline Had loss of appetite & $22(76)$ & $30(88)$ & & 0.20 \\
\hline Had pain & $20(69)$ & $29(85)$ & & 0.12 \\
\hline Had dyspnoea & $18(62)$ & $17(52)$ & & 0.40 \\
\hline Had mouth or mucous problems & $18(62)$ & $16(49)$ & & 0.28 \\
\hline Was incontinent & $20(69)$ & $13(38)$ & & 0.015 \\
\hline Had nausea & $9(32)$ & $10(30)$ & & 0.88 \\
\hline Had bedsores & $5(17)$ & $13(38)$ & & 0.07 \\
\hline Was confused & $14(48)$ & $10(29)$ & & 0.12 \\
\hline Suffered from anxiety & $12(41)$ & $5(15)$ & & 0.021 \\
\hline Was depressed & $3(10)$ & $2(6)$ & & 0.54 \\
\hline \multicolumn{5}{|l|}{ Evaluation of care during the last 3 days of life $[n(\%)]$} \\
\hline Assistance with personal care was sufficient & $27(93)$ & $32(94)$ & & 0.87 \\
\hline Nursing care was sufficient ${ }^{\mathrm{a}}$ & $26(90)$ & $33(97)$ & & 0.23 \\
\hline Relative was involved in decision-making & $25(89)$ & $33(97)$ & & 0.22 \\
\hline Relative was sufficiently involved in decision-making & $24(89)$ & $33(100)$ & & 0.049 \\
\hline Patient might have disagreed with medical decision(s) & $4(15)$ & $1(3)$ & & 0.10 \\
\hline Relative disagreed with medical decision(s) & $7(24)$ & $7(21)$ & & 0.78 \\
\hline It had been clear that patient was dying & $18(67)$ & $26(79)$ & & 0.29 \\
\hline
\end{tabular}

${ }^{a}$ Including patients who did not need professional nursing care 
Table 5 Dying in an institution or at home: experiences of bereaved relatives

\begin{tabular}{|c|c|c|c|}
\hline & \multicolumn{2}{|l|}{ Place of death } & \multirow[t]{2}{*}{$P$ value $\chi^{2}$ test } \\
\hline & $\begin{array}{l}\text { In institution }(N=29) \\
n(\%)\end{array}$ & At home $(N=34)$ & \\
\hline How often did you see patient in the last months of life? & & & 0.78 \\
\hline Every day & $24(83)$ & $29(85)$ & \\
\hline Less than daily & $5(17)$ & $5(15)$ & \\
\hline Did caring for patient affect your own social life? & & & 0.068 \\
\hline Yes & $22(76)$ & $32(94)$ & \\
\hline No & $7(24)$ & $2(6)$ & \\
\hline Did caring for patient result in financial problems? & & & 0.17 \\
\hline Yes & $4(14)$ & $1(3)$ & \\
\hline No & $25(86)$ & $33(97)$ & \\
\hline Did you receive support from your family in caring for patient? & & & 1.0 \\
\hline Much support & $16(55)$ & $23(68)$ & \\
\hline Some or no support & $13(45)$ & $11(32)$ & \\
\hline Did caring for patient affect your own health? & & & 0.62 \\
\hline Yes & $12(41)$ & $12(35)$ & \\
\hline No & $17(59)$ & $22(65)$ & \\
\hline Did caring for patient cost you a lot of energy? & & & 0.96 \\
\hline Often or all the time & $15(52)$ & $15(44)$ & \\
\hline Rarely or sometimes & $14(48)$ & $19(56)$ & \\
\hline How important was being involved with care for patient for you? & & & 0.65 \\
\hline Very important & $26(90)$ & $32(94)$ & \\
\hline Important & $3(10)$ & $2(6)$ & \\
\hline
\end{tabular}

involved in the decision-making, whereas all relatives in the other group were satisfied about their level of involvement.

Further, of the bereaved relatives who had cared for a patient who died in an institution, 76\% reported that it had significantly affected their own social life; this percentage was $94 \%$ for relatives who had cared for a patient who died at home (Table 5). A substantial number of relatives had only received some or no support from other family members (38\%), and the number of relatives who reported that their own health had been affected by caring for the patient was also quite large (38\%). Caring for a dying relative rarely yielded financial problems. Nearly all relatives thought it very important that they had been involved in caring for the patient.

\section{Discussion}

Medical care for patients who are in the last stage of life has received much attention during the past decade in The Netherlands. The organization of health care services for terminally ill patients has greatly expanded during a 5-year period from 1998 through 2003, during which the government financially supported six university-based centers for the further development of end-of-life care. After this period, the government took the position that, whereas death and dying are common events, the provision of end- of-life care should be part of the professional skills of all physicians, including general practitioners providing endof-life care to patients who are staying at home. For complex problems, general practitioners and other physicians can now, in many places, seek support from expert teams [20-22].

Of the 103 patients in this study, who were, at inclusion, all treated as outpatients by a clinical specialist, about half died in their own home. Death in an institution mostly concerned a hospital, which was probably not, for all patients, foreseen as the place of dying. Patient characteristics did not clearly determine the place of dying in our study. Whether or not patients lived with a partner was the only variable that was significantly associated with the place of dying. Having access to informal care support is invariably found to be a strong determinant of being able to die at home [4]. Other factors that have been found to affect rates of dying at home are the health status and emotional capacity of the main carer, the availability and use of home-based end-of-life care services, the need for specialist symptom control, tumor type, distance to inpatient services, gender and age of the patient, the patient's socio-economic status, and strength and visibility of patient or carer preferences concerning the place and circumstances of dying [4, 23-26]. Obviously, the number of cases in our study was limited, and we did not assess all possibly relevant factors, which precludes firm conclusions on determinants of the place of dying. However, 
whereas access to the available public end-of-life care services, both institutional and home-based, is virtually unlimited in The Netherlands and financially covered by either private or public insurance, care needs of patients are probably a predominant factor.

The availability of in- and outpatient end-of-life care services is probably another important determinant of place of death. The number of patients who died in a specialized end-of-life care service in our study was limited. National statistics on the place of dying does not include hospices or end-of-life care units as a separate category. However, the percentage of cancer deaths inside such services as found in our study is probably comparable to the percentage in the total Dutch population. Recently, the number of beds in specialized end-of-life care services in The Netherlands has been rapidly increasing [27]. It is, therefore, likely that the proportion of cancer deaths in end-of-life care services will further increase in the coming years. However, the extent to which dying in an end-of-life care service will substitute dying in a hospital or dying at home is hard to predict. Probably, institutional end-of-life care services address very diverse needs of dying patients and their caregivers. Further, financial and other incentives that are aimed at setting the course for the supply of end-of-life care services may affect developments concerning the place of dying and end-of-life care as well [27].

It is remarkable that a substantial number of patients in our study did not have a clear preference concerning their place of dying. Obviously, we only have information about the preferences that patients had discussed with their interviewed relative. Patients may also have had wishes that relatives were not aware of. Nevertheless, the data in our study suggest that the place of dying is not a great concern for a substantial number of terminally ill cancer patients in The Netherlands.

In general, we found few differences in the evaluation by physicians and bereaved relatives of the dying phase of patients who died in an institution and patients who died at home. Patients who died in an institution were, according to their physicians, less often ready to die, which may be due to the fact that hospitalization is typically forgone in patients who are expected to die at short notice. A sudden and more rapid deterioration than expected may also have been among the reasons to admit patients to hospital shortly before dying in some cases. We did not find substantial differences between both settings in most end-of-life decision-making characteristics. Relatives in both settings quite often $(21-24 \%)$ stated that they had not agreed with the decision-making. Relatives of patients who died in an institution somewhat less often than other relatives felt that they had been sufficiently involved in the decision-making. Dissatisfaction of relatives with end-of-life decision-making in an institutional setting has been described elsewhere too
[28-30] and has been attributed to many factors, such as a lack of time of professional caregivers, lack of skills in communication, failure to recognize end-of-life decisionmaking as a subject that could be discussed, ethical barriers, and the lack of emotional support for relatives [28-32]. It is unclear if our finding that relatives of patients who died outside an institutional setting more often feel satisfied about their involvement in the decision-making process is due to better communication in the home situation. However, the general practitioner, who often has a longstanding relationship with patients and their families, typically plays a key role in end-of-life care at home and may be better able to adequately communicate with family than institutional caregivers [33]. Medical decision-making may also be less complex or controversial for patients who die at home.

The possibly rather complex decision-making in institutions is not associated with a higher prevalence of most symptoms. Fatigue, pain, and dyspnoea were among the most common symptoms in both settings, as has been found elsewhere too [34]. Incontinence was more common among patients dying in an institution, and this also holds for anxiety, which was reported as a problem for almost half of all patients dying in an institution. Incontinence and mental status have elsewhere also been found to be associated with a need of nursing home care [35]. In contrast, bedsores were more common at home.

Virtually all relatives in both settings were satisfied about the personal and nursing care that had been provided to their dying relative. This may, to some extent, be indicative of the relative quality of end-of-life care in institutions and at home, but using satisfaction as an absolute indicator of the quality of palliative care services is quite problematic [36]. Further, most relatives were closely involved and appreciated their personal involvement very much, both for patients who died in an institution and patients who died at home. Nevertheless, caring for a dying relative often affected their own social life, especially when dying occurred at home, and took a lot of energy.

Our study has several limitations. Firstly, the patients' perspectives on their own dying process is lacking. Bereaved family members' assessments are known to sometimes disagree with those of the patients', especially for subjective aspects such as psychological symptoms and pain [37]. This is also true for physicians' assessment of their patients' condition. Secondly, our group of patients is probably not representative for all patients dying from one of the five major types of cancer because patients with a very poor health status and patients who died shortly after the diagnosis of incurable cancer were not included in the cohort study upon which the data collection for this study was based. Moreover, data from bereaved relatives could only be obtained for $61 \%$ of all patients, which may have 
resulted in an overestimation of the degree of satisfaction of relatives. The fact that patients of whom no bereaved relative participated in the study had a shorter disease duration at inclusion than other patients suggests that a rapidly progressive disease process makes it more difficult for bereaved relatives to talk about the last phase of life of the patient.

In summary, we did not find major differences in the process and quality of dying between institutional settings and the home setting. Most patients with clear preferences concerning their place of dying were able to die at their preferred place. In about half of all cases, relatives were not aware of any preference of the patient concerning the place of dying, which is apparently not a major concern for many people. We conclude that the current situation in The Netherlands, in which the place of dying is mainly determined by the availability of informal caregivers at home and the care needs of the patient, involves no major threats to the process and quality of dying.

Acknowledgment We are very grateful to the patients and their relatives who participated in this study, to the medical doctors who invited the patients to participate and filled out questionnaires, and to the oncology nurses who were very supportive during the data collection. The study was supported by the Dutch Ministry of Health, Welfare and Sport, the Center for Development of Palliative Care in Rotterdam, The Netherlands, and the Comprehensive Cancer Center South in Eindhoven, The Netherlands.

\section{References}

1. Anthony S, Buitendijk SE, Offerhaus PM, van Dommelen P, van der Pal-de Bruin KM (2005) Maternal factors and the probability of a planned home birth. BJOG 112:748-753

2. van der Heide A, Deliens L, Faisst K et al (2003) End-of-life decision-making in six European countries: descriptive study. Lancet 362:345-350

3. Statistics Netherlands (2006) Available at http://www.cbs.nl/en$\mathrm{gb} / \mathrm{menu} /$ themas/mens-maatschappij/bevolking/publicaties/arti kelen/archief/2004/2004-1483-wm.htm. Accessed 27 April 2006

4. Gomes B, Higginson IJ (2006) Factors influencing death at home in terminally ill patients with cancer: systematic review. BMJ 332:515-521

5. Bruera E, Sweeney C, Russell N, Willey JS, Palmer JL (2003) Place of death of Houston area residents with cancer over a twoyear period. J Pain Symptom Manage 26:637-643

6. Higginson IJ, Sen-Gupta GJA (2000) Place of care in advanced cancer: a qualitative systematic literature review of patient preferences. J Palliat Med 3:287-300

7. Thomas C, Morris SM, Clark D (2004) Place of death: preferences among cancer patients and their carers. Soc Sci Med 58:2431-2444

8. Davies E, Higginson IJ (eds) (2004) Better palliative care for older people. World Health Organisation, Copenhagen

9. Ahlner-Elmqvist M, Jordhoy MS, Jannert M, Fayers P, Kaasa S (2004) Place of death: hospital-based advanced home care versus conventional care. A prospective study in palliative cancer care. Palliat Med 18:585-593
10. Grande GE, Addington-Hall JM, Todd CJ (1998) Place of death and access to home care services: are certain patient groups at a disadvantage? Soc Sci Med 47:565-579

11. Peters L, Sellick K (2006) Quality of life of cancer patients receiving inpatient and home-based palliative care. J Adv Nurs 53:524-533

12. Voogt E, van der Heide A, Rietjens JA et al (2005) Attitudes of patients with incurable cancer toward medical treatment in the last phase of life. J Clin Oncol 23:2012-2019

13. van der Maas PJ, van der Wal G, Haverkate I et al (1996) Euthanasia, physician-assisted suicide, and other medical practices involving the end of life in The Netherlands, 1990-1995. N Engl J Med 335:1699-1705

14. Aaronson NK, Ahmedzai S, Bergman B et al (1993) The European organization for research and treatment of cancer QLQ-C30: a quality-of-life instrument for use in international clinical trials in oncology. J Natl Cancer Inst 85:365-376

15. Kaasa S, Bjordal K, Aaronson N et al (1995) The EORTC core quality of life questionnaire (QLQ-C30): validity and reliability when analysed with patients treated with palliative radiotherapy. Eur J Cancer 31A:2260-2263

16. Osse BH, Vernooij-Dassen MJ, Schade E et al (2002) Problems to discuss with cancer patients in palliative care: a comprehensive approach. Patient Educ Couns 47:195-204

17. Osse BH, Vernooij MJ, Schade E, Grol RP (2004) Towards a new clinical tool for needs assessment in the palliative care of cancer patients: the PNPC instrument. J Pain Symptom Manage 28:329341

18. Addington-Hall JM, McCarthy M (1995) The regional study of care for the dying: methods and sample characteristics. Palliat Med 9:27-35

19. Nijboer C, Triemstra M, Tempelaar R, Sanderman R, van den Bos GA (1999) Measuring both negative and positive reactions to giving care to cancer patients: psychometric qualities of the Caregiver Reaction Assessment (CRA). Soc Sci Med 48:12591269

20. Gordijn B, Janssens R (2000) The prevention of euthanasia through palliative care: new developments in The Netherlands. Patient Educ Couns 41:35-46

21. Smeenk FW, de Witte LP, Nooyen IW, Crebolder HF (2000) Effects of transmural care on coordination and continuity of care. Patient Educ Couns 41:73-81

22. Francke AL, Kerkstra A (2000) Palliative care services in The Netherlands: a descriptive study. Patient Educ Couns 41:23-33

23. Degenholtz HB, Rhee Y, Arnold RM (2004) Brief communication: the relationship between having a living will and dying in place. Ann Intern Med 141:113-117

24. Fukui S, Fukui N, Kawagoe H (2004) Predictors of place of death for Japanese patients with advanced-stage malignant disease in home care settings: a nationwide survey. Cancer 101:421-429

25. Chvetzoff G, Garnier M, Perol D et al (2005) Factors predicting home death for terminally ill cancer patients receiving hospitalbased home care: the Lyon comprehensive cancer center experience. J Pain Symptom Manage 30:528-535

26. Burge F, Lawson B, Johnston G (2003) Trends in the place of death of cancer patients, 1992-1997. CMAJ 168:265-270

27. Mistiaen P, van Hasselt TJ, Francke A (2005) Monitor palliatieve zorg. Rapport 2005. Nivel, Utrecht

28. Teno JM, Clarridge BR, Casey V et al (2004) Family perspectives on end-of-life care at the last place of care. JAMA 291:88-93

29. Levy MM (2001) End-of-life care in the intensive care unit: can we do better? Crit Care Med 29(2 Suppl):N56-N61

30. Baker R, Wu AW, Teno JM et al (2000) Family satisfaction with end-of-life care in seriously ill hospitalized adults. J Am Geriatr Soc 48(5 Suppl):S61-S69 
31. Tulsky JA (2005) Interventions to enhance communication among patients, providers, and families. J Palliat Med 8(Suppl 1):S95-S102

32. Tulsky JA (2005) Beyond advance directives: importance of communication skills at the end of life. JAMA 294:359-365

33. Borgsteede SD, Graafland-Riedstra C, Deliens L et al (2006) Good end-of-life care according to patients and their GPs. Br J Gen Pract 56:20-26

34. Solano JP, Gomes B, Higginson IJ (2006) A comparison of symptom prevalence in far advanced cancer, AIDS, heart disease, chronic obstructive pulmonary disease and renal disease. J Pain Symptom Manage 31:58-69
35. Friedman SM, Steinwachs DM, Temkin-Greener H, Mukamel DB (2006) Informal caregivers and the risk of nursing home admission among individuals enrolled in the program of allinclusive care for the elderly. Gerontologist 46:456-463

36. Aspinal F, Addington-Hall J, Hughes R, Higginson IJ (2003) Using satisfaction to measure the quality of palliative care: a review of the literature. J Adv Nurs 42:324-339

37. McPherson CJ, Addington-Hall JM (2004) Evaluating palliative care: bereaved family members' evaluations of patients' pain, anxiety and depression. J Pain Symptom Manage 28:104-114 